\title{
Bilateral sequential atypical femur fractures in a patient on zoledronic acid therapy: a case report and review of literature
}

\author{
Radhakrishna Kantanavar, Mohan Madhav Desai, Kunal Ajitkumar Shah*, \\ Swapneel Sunil Shah
}

\begin{abstract}
Department of Orthopedics, Seth Gordhandas Sunderdas Medical College and King Edward Memorial Hospital, Mumbai, Maharashtra, India
\end{abstract}

Received: 03 September 2019

Accepted: 11 October 2019

*Correspondence:

Dr. Kunal Ajitkumar Shah,

E-mail: kunalajitshah@gmail.com

Copyright: () the author(s), publisher and licensee Medip Academy. This is an open-access article distributed under the terms of the Creative Commons Attribution Non-Commercial License, which permits unrestricted non-commercial use, distribution, and reproduction in any medium, provided the original work is properly cited.

\begin{abstract}
Bisphosphonates are mainstay of anti-resorptive therapies for osteoporosis. They prevent osteoporotic fractures by 40 to $70 \%$ in women and men with osteoporosis. Use of these medications is not free from complications. A case of 62 year old female who presented with left thigh pain after trivial fall at home. X-ray diagnosed as atypical femur fracture of left femur which was fixed internally with interlock nailing. On $1^{\text {st }}$ postoperative day, she complained of pain in right thigh. X-ray revealed an atypical femur fracture of left femur shaft which was also fixed internally with nailing. Biochemical investigations were suggestive of effectiveness of zoledronic therapy. We report this first case of bilateral sequential atypical femur fractures that was treated with zoledronate for 2 years. To our knowledge there are reports of oral alendronate therapy with atypical femoral fractures but none on zoledronic acid.
\end{abstract}

Keywords: Atypical femur fractures, Zoledronic acid, Bisphosphonates

\section{INTRODUCTION}

Bisphosphonates (BPs) are the mainstay of antiresorptive therapies for osteoporosis. In randomized controlled trials (RCTs), this class of drugs has been shown to prevent osteoporotic fractures by 40 to $70 \%$ in women and men with osteoporosis. ${ }^{1}$ However the use of these medications is not free from complications. Case reports of unusual fragility fractures in the subtrochanteric and femoral shaft (ST/FS) regions in patients treated with BPs were first reported in 2005 by Odvina et al. ${ }^{2}$

To our knowledge, we present the first reported case of bilateral sequential atypical femur fractures (AFFs) that was treated with zoledronate for two years. Patient was also a known case of rheumatoid arthritis.

\section{CASE REPORT}

A 62 year old female presented to a tertiary care hospital in June 2019 with pain in left thigh since one month. Pain acutely increased after history of trivial trauma at home. Examination revealed swelling of left thigh, movements of left hip and knee were painful and distal pulses present with intact motor and sensory functions. She was known case of rheumatoid arthritis and osteoporosis. Two doses of intravenous zoledronate $5 \mathrm{mg}$ were administered in November 2017 and December 2018. She had undergone bilateral total knee replacement 14 years back.

She underwent X-rays of left thigh which were suggestive of left atypical femur shaft fracture (Figure 1). According to the American Society for Bone and Mineral Research Task Force 2013 revised case definition of AFFs, (Table 1) all five major features and two of the four minor features are present in this patient. On 
biochemical tests, normal levels of serum calcium 9.0 $\mathrm{mg} \%$, serum phosphorous $4.2 \mathrm{mg} \%$, serum Vitamin D3 $34 \mathrm{ng} / \mathrm{mL}$, serum parathyroid hormone $18 \mathrm{ph} / \mathrm{mL}$ were found. We found plasma beta2 Crosslaps (C-telopeptides) level $171.3 \mathrm{pg} / \mathrm{ml}$ (Normal range 50-450), serum P1NP (total procollagen type 1 amino-terminal propeptide)
$59.03 \mathrm{ng} / \mathrm{ml}$ (normal range 37 - 64), indicating effectiveness of anti-resorptive therapy. Bone mineral density (BMD) measured by dual-energy $\mathrm{x}$-ray absorptiometry DXA (Hologic 4500@) was consistent with osteoporosis. Right femoral neck, $0.503 \mathrm{~g} / \mathrm{cm}^{2}(\mathrm{~T}-$ score $=-3.1)$; right total hip, $0.657 \mathrm{~g} / \mathrm{cm}^{2}(\mathrm{~T}$-score $=-2.3)$.

Table 1: American Society for Bone and Mineral Research Task Force 2013 revised case definition of atypical femur fractures.

\begin{tabular}{|ll|}
\hline $\begin{array}{l}\text { Sr. } \\
\text { No. }\end{array}$ & $\begin{array}{l}\text { Findings in } \\
\text { patient }\end{array}$ \\
\hline \begin{tabular}{l} 
Major criteria \\
\hline 1. $\quad$ The fracture is associated with minimal or no trauma, as in a fall from a standing height or less
\end{tabular} & Present \\
\hline 2. $\quad \begin{array}{l}\text { The fracture line originates at the lateral cortex and is substantially transverse in its orientation, } \\
\text { although it may become oblique as it progresses medially across the femur }\end{array}$ & Present \\
\hline 3. $\quad \begin{array}{l}\text { Complete fractures extend through both cortices and may be associated with a medial spike; } \\
\text { incomplete fractures involve only the lateral cortex }\end{array}$ & Present \\
\hline 4. $\quad$ The fracture is noncomminuted or minimally comminuted & Present \\
\hline 5. $\quad \begin{array}{l}\text { Localized periosteal or endosteal thickening of the lateral cortex is present at the fracture site } \\
\text { Minor criteria }\end{array}$ & Present \\
\hline 1. $\quad$ Generalized increase in cortical thickness of the femoral diaphyses & Present \\
\hline 2. $\quad$ Unilateral or bilateral prodromal symptoms such as dull or aching pain in the groin or thigh & Present \\
\hline 3. $\quad$ Bilateral incomplete or complete femoral diaphysis fractures & Absent \\
\hline 4. $\quad$ Delayed fracture healing & Absent \\
\hline
\end{tabular}

*To satisfy the case definition of AFF, the fracture must be located along the femoral diaphysis from just distal to the lesser trochanter to just proximal to the supracondylar flare. In addition, at least four of five major features must be present. None of the minor features is required but have sometimes been associated with these fractures.

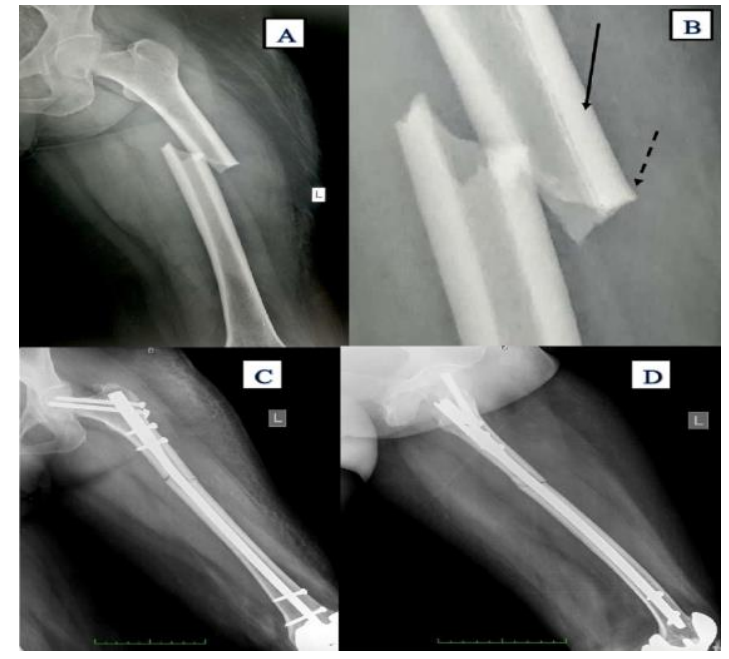

Figure 1: (A) Left femur shaft fracture, typically in the location between lesser trochanter and supracondylar flare, the fracture line originates at the lateral cortex and is substantially transverse in its orientation. It becomes oblique as it progresses medially across the femur associated with a medial spike with thickening of the lateral cortex; (B) Localized endosteal thickening of the lateral cortex (solid arrow) and typical "beaking" at the fracture site in lateral cortex (dotted arrow); (C) and (D)

Postoperative $x$-rays with fixation of fracture. Screws were put through neck of femur to splint it.

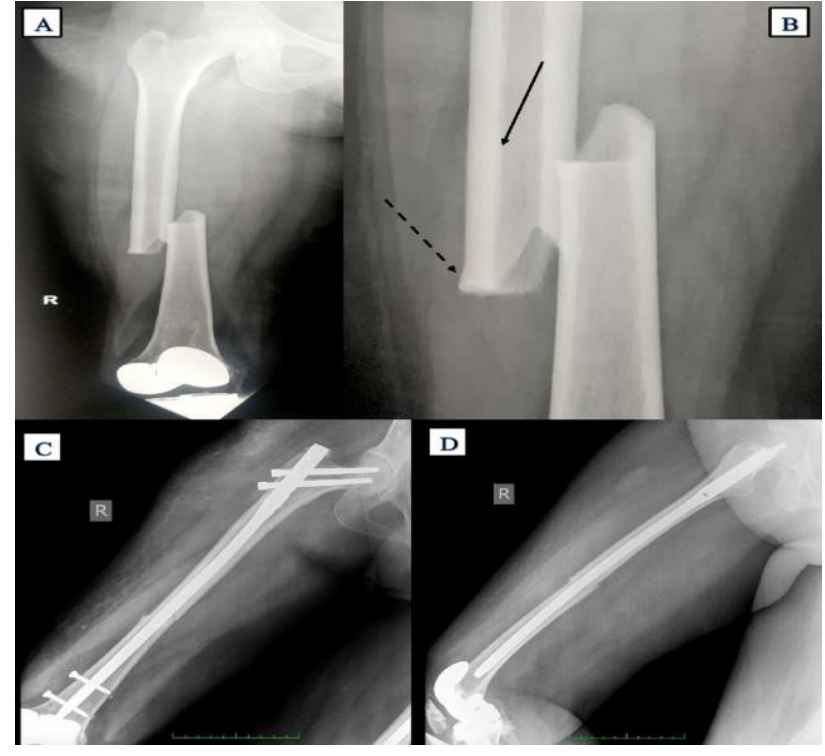

Figure 2: (A) Right atypical femur fracture; (B)

Localised endosteal thickening (solid arrow) and typical "beaking" of lateral cortex at the fracture site (dotted arrow); (C) and (D): Post-operative X-rays after fixation of fracture.

Patient was managed with closed reduction and internal fixation with antegrade femur interlock nail, two $6.5 \mathrm{~mm}$ cannulated cancellous screws were put missing the nail to splint the neck of femur to prevent fragility fractures of 
neck (Figure 1). On first postoperative day the patient complained of pain and swelling in the right thigh. There was no history of trauma, on examination painful range of motion of right hip and knee with distal pulses present and intact motor and sensory functions. X-rays were suggestive of right atypical femur fracture. Patient was managed with closed reduction and internal fixation with femur nail (Figure 2). Patient was mobilized full weight bearing as per her pain tolerance. Inj. zoledronate was discontinued and inj. teriparatide $20 \mu \mathrm{g} / 80 \quad \mu \mathrm{l}$ subcutaneous daily, calcium and vitamin D supplements were started. Patient counselled regarding risk of delayed union, non-union and need for secondary procedures.

\section{DISCUSSION}

It is unclear, why BPs effectively reduces fracture risk for many types of fracture but become harmful at a single fracture location only in a small percentage of individuals. Micro damage is an energy dissipating mechanism, as stated by Frost in his Mechanostat model of bone turnover. ${ }^{3}$ Small diffuse cracks form under tension and longer micro cracks form under compression. Cracked region of the bone can't be recracked to release energy unless it is remodelled. Remodelling is a coupled process with synchrony between osteoclastic bone resorption and osteoblastic bone formation. There are two types of remodelling which are targeted and stochastic (no specific site). Bisphosphonate treatment suppresses not only stochastic remodelling but also the targeted repair of micro damage. ${ }^{4}$ By reducing bone turnover, BP treatment leads to increased matrix mineralization but also increases accumulation of micro damage and nonenzymatic collagen cross-links. This has negative impact on bone matrix properties and contributing to the pathogenesis of atypical femoral fractures (AFFs). ${ }^{5}$ BPs are also known to localize at sites where bone turnover is high, which includes a healing fracture site. By reducing bone remodelling preferentially at micro cracks, BPs negatively affect the repair of micro damage and impending micro crack. Over a period of time, these cracks progress or coalesce with other cracks to create a fracture due to inhibition of repair mechanisms. ${ }^{5}$

In a multi-centric study, 76 cases of AFFs were retrospectively analysed for BMD, prodromal symptoms, and medication history for osteoporosis. Twenty-two patients $(28.9 \%)$ suffered from prodromal symptoms, 43 $(56.5 \%)$ had delayed fracture union and bilateral femoral fractures developed in $23(30.2 \%) .^{6}$ Thus it is of prime importance to ask for the prodromal symptoms when patient on bisphosphonates comes for follow up. Bilateral fractures is as high as $30 \%$, so incomplete fractures on opposite side can be diagnosed and managed with prophylactic intramedullary nailing. ${ }^{7}$

Patients with an AFF are at a significantly higher risk of delayed healing, non-union and a need for secondary procedures compared with patients with typical femur fractures. In a study of 17 AFFs in 15 patients only $54 \%$ of patients healed their fractures following surgical treatment. The other $46 \%$ of patients required a secondary revision procedure to achieve fracture healing. ${ }^{8}$ Another study of 33 patients with AFFs undergoing surgical treatment, $30.3 \%$ did not heal and required a secondary procedure to achieve fracture healing. ${ }^{9}$ Similarly in a study of 42 patients with 48 fractures, Cho et al reported a primary healing rate of $68.7 \%$ with a mean time to union of 10.7 months. ${ }^{10}$

\section{CONCLUSION}

Improved understanding of AFF risk factors and pathophysiology could help to identify which patients are at highest risk for AFFs prior to starting therapy. Opposite thigh radiographs are necessary to diagnose impending fracture and prophylactic fixation of such fractures is important. Delayed union is a known fact and secondary surgeries are commonly required.

\section{Funding: No funding sources Conflict of interest: None declared Ethical approval: Not required}

\section{REFERENCES}

1. Khosla S, Bilezikian JP, Dempster DW, Lewiecki EM, Miller PD, Neer RM, et al. Benefits and risks of bisphosphonate therapy for osteoporosis. J Clin Endocrinol Metab. 2012;97:22720-82.

2. Odvina CV, Zerwekh JE, Rao DS, Maalouf N, Gottschalk FA, Pak CYC. Severely suppressed bone turnover: A potential complication of alendronate therapy. J Clin Endocrinol Metab. 2005;90:1294301.

3. Frost HM. Perspectives: a proposed general model of the "Mechanostat" (Suggestions from a new skeletal-biologic paradigm). Anat Rec. 1996;244:139-47.

4. Li J, Mashiba T, Burr DB. Bisphosphonate treatment suppresses not only stochastic remodeling but also the targeted repair of microdamage. Calcif Tissue Int. 2001;69:281-6.

5. Ettinger B, Burr DB, Ritchie RO. Proposed pathogenesis for atypical femoral fractures: lessons from materials research. Bone. 2013;55:495-500.

6. Kang JS, Won YY, Kim JO, Min BW, Lee KH, Park KK, et al. Atypical femoral fractures after antiosteoporotic medication: A Korean multicenter study. Int Orthop. 2014;38:1247-53.

7. Yoon RS, Beebe KS, Benevenia J. Prophylactic bilateral intramedullary femoral nails for bisphosphonate-associated signs of impending subtrochanteric hip fracture. Orthopedics. 2010;33(4).

8. Weil YA, Rivkin G, Safran O, Liebergall M, Foldes AJ. The outcome of surgically treated femur fractures associated with long-term bisphosphonate use. J Trauma Inj Infect Crit Care. 2011;71:186-90. 
9. Teo BJX, Koh JSB, Goh SK, Png MA, Chua DTC, Howe TS. Post-operative outcomes of atypical femoral subtrochanteric fracture in patients on bisphosphonate therapy. Bone Jt J. 2014;96:658-64.

10. Cho JW, Oh CW, Leung F, Park KC, Wong MK, Kwek E, et al. Healing of atypical subtrochanteric femur fractures after cephalomedullary nailing: which factors predict union?. J Orthop Trauma. 2017;31:138-45.

Cite this article as: Kantanavar R, Desai MM, Shah KA, Shah SS. Bilateral sequential atypical femur fractures in a patient on zoledronic acid therapy- a case report and review of literature. Int J Res Orthop 2019;5:1211-4. 